\title{
Comentário IX
}

\author{
Sheila de Castro Faria \\ Departamento de História, Instituto de Ciências \\ Humanas e Filosofia/Universidade Federal \\ Fluminense
}

Delimitar conceitos e estabelecer campos para determinado grupo de conhecimentos, principalmente se estão marcados por uma novidade às vezes aparente, sempre foi tarefa árdua. Os debates historiográficos, no século XX, estão repletos de exemplos marcantes, alguns até mesmo divertidos; outros, muito grosseiros. As farpas e as ironias com freqüência tomam a vez das discussões realmente produtivas.

O que parece ocorrer é que, em determinado momento, certo tema, acompanhado de métodos e técnicas mais especííicos, coloca-se como objeto privilegiado do historiador leu poderia dizer do pesquisador ou estudioso, em geral, mas creio que é melhor reduzir estas observações ao campo da História) e as direções diferentes esbarram, muitas vezes, nas concepções já arraigadas ou mais fixamente estruturadas. Albert Soboul, num colóquio na França, em 1965, reclamava que a história social não podia ser um simples apêndice da história econômica (cf. Godinho \& Labrousse 1973). Mesmo já bem delimitada, ele ainda reafirmava a necessidade de um espaço maior e específico para ela. A história econômica, por sua vez, desdobrou-se em outras: história da agricultura, história agrária, história econômica do mundo rural, história das empresas, etc., com várias divergências, além de produzir novos conceitos. A demografia criou a demografia histórica ou história demográfica (sendo a escolha do título ainda um debate a mais). Em suma, os exemplos se repetem de maneira surpreendente.

A escolha dos historiadores por certos temas também torna-se problemática e é vista, dependendo do caso, com suspeita. Michel Vovelle teve 
de agüentar severas críticas e fazer esforços para justificar como um historiador publicamente marxista poderia se envolver tanto com um tema ligado à então ainda adolescente História das Mentalidades.

Sem dúvida, a chamada História das Mentalidades teve, na época, um impacto bem mais marcante do que as subdivisões de outros campos da História, como o econômico e o políico, por exemplo, não só pela novidade dos objetos (criança, familia, sexualidade, amor, morte, etc.) como, e principalmente, porque foi acompanhada de uma grande aceitação por parte do mercado editorial. Houve ônus: a perda acadêmica foi o sumiço das referências bibliográficas e das comprovações empíricas, chegando mesmo a ponto de um historiador do porte de George Duby desdenhar notas e citações em seus últimos livros. Afastava-se, assim, a "chatice" acadêmica. Não cabe, aqui, tentar explicar os motivos dos sucessos editoriais que significaram a extrapolação do meio acadêmico, mas sim constatar o fato de que os temas ligados à História das Mentalidades provocaram diálogos amplos com outras áreas do conhecimento (Psicologia, Antropologia, Filosofia, Lingüística, etc.), com certeza resultado considerado favorável para muitos estudiosos, e suscitaram interesse de leigos.

Decorrência de inúmeros debates, apesar de reconhecida na academia como um campo específico do saber, a História das Mentalidades continuou mudando - inclusive de nome.

O que se pretende com mudanças de títulos não deixa de ser uma certa oposição ao que se tinha antes. É uma questão de diferenciação, de identidade, em suma. Ao mesmo tempo em que se podem estabelecer filiações, por outro lado a incorporação de "novos objetos, novas abordagens e novos problemas" necessita de redefinição também de símbolos. Torna-se uma atitude didática.

A partir do momento em que se cria e se justifica o fítulo, a nivel acadêmico, mesmo com a resistência de alguns, outro problema a ser enfrentado é o de discutir sobre o que se supõe "pertencer a" ou "estar contido em", para usar uma linguagem matemática. Definir limites e fronteiras é, portanto, um outro passo, talvez tão complicado quanto o primeiro.

São estes os assuntos, no geral, de que trata Ronaldo Vainfas, com a temática específica da História da Vida Privada, algumas vezes de forma provocativa e outras, um tanto adequadamente irônica. Não é para menos que, logo no início do texto, o autor alerte para a "imprecisão vocabular" com que iniciou o tratamento do termo. Creio ter sido intencional e estratégico este procedimento. Sua conclusão sugere que símbolos diferentes podem estar significando a mesma coisa, se não estou enganada.

Com o aporte de sua já tradicional e conhecida erudição, Ronaldo Vainfas sempre interessou-se pelos debates teóricos sobre História e disciplinas afins, o que me deixa um pouco sem jeito para afirmar que o aprisionamento dos objetos de pesquisa em "campo de investigação, objeto da história, território de pesquisa, tema" ou qualquer outra "imprecisão vocabular" que se queira, torna-se um pouco estéril. Compreendo a importância até mesmo política da circunscrição de abordagens e a necessidade de uma "precisão vocabular", quando discutimos nossos objetos, mas, como pesquisadora e historiadora, não acharia produtivo discutir exaustivamente, por exemplo, sob que título o trabalho que realizo se insere. 
Os objetos de investigação podem e devem ser enquadrados em diversas temáticas, já que há certamente grandes espaços de interseção entre os campos da história, além de estes campos não serem nunca fixos - variam amplamente, no tempo e mesmo no espaço. Difíceis e trabalhosas, portanto, tornam-se as tentativas de limitar fronteiras muito rígidas, tomando o tempo de atitudes mais profícuas como as de fazer pesquisa, entre outras.

"Apesar deste declarado manifesto contra, digo claramente, "ífulos", falemos deles. Creio que o autor toca em alguns pontos bastante interessantes, com alguns dos quais concordo.

O primeiro é a crítica à rigidez de Duby ao delimitar a vida privada pela negação, além de, em particular, opô-la a "cotidiano", como se a vida privada não fosse "cotidiana". Neste aspecto, particularmente, utilizo história do cotidiano no sentido mais lato possível, seguindo o significado que tem a palavra hoje em dia - repetição: aquilo que sucede ou se pratica habitualmente. Sendo assim, não posso circunscrever o cotidiano à casa, nem mesmo ao espaço físico da casa. Muito menos ainda ao quarto ou ao leito, como alude Duby, embora todos sejam também lugares por excelência do cotidiano. Sinto ser lógico, portanto, pensar a noção de cotidiano até mesmo nas práticas produtivas, econômicas, coletivas ou individuais, pois não é possivel separar trabalho lou mesmo o não-trabalhol - qualquer que seja e onde quer que esteja - do cotidiano.

É verdade que pode ser argumentado que somente há pouco tempo se estabeleceu uma divisão clara entre local de dormir e de trabahar, particularmente com o aumento da urbanização, pois, pelo menos no ocidente, os lugares de morar e de produzir estavam quase sempre sobrepostos. Justifica-se mais ainda, então, inclusive historicamente, considerar como cotidiano o movimento das permanências e as rupturas do que se praticava no dia-a-dia das pessoas e/ou grupos sociais, incluindo o estudo das formas de produção.

Do mesmo modo, penso ser inimaginável separar "vida privada" do cotidiano, qualquer que seja a interpretação sobre o "privado" de qualquer época que se queira dar. Por mais que Duby possa ter razão em afirmar que sempre houve no vocabulário (pelo menos ocidental e, com certeza, francês) uma diferenciação do que seria "privado" e "público", dificilmente nos podemos convencer de que o "privado" sempre se tenha referido ao espaço doméstico, à "domesticidade", como se a "domesticidade" estivesse ligada ao "escondido". Ronaldo Vainfas tem razão quando, num exemplo, afirma não haver nada mais "privado" |longe dos othares, "escondido"l, na sociedade colonial brasileira, do que práticas sexuais realizadas fora das casas de morada - matos e similares. $\bigcirc$ mesmo pode-se dizer de "público". O "privado", portanto, mesmo existindo enquanto conceito em diversas épocas, teve seus lugares de realização variando enormemente.

Podemos concluir, então, que o que se quer estudar, quando os autores se referem à "vida privada" ligada à noção de "domesticidade", é o que entendemos hoje como privacidade, os lugares onde pode ser exercida. E que se vão buscar este mesmo objeto e seus lugares no tempo histórico. Corre-se o risco, com este procedimento, de não se dar uma othadela para, por exemplo, o mato, lugar "naturalmente" público, e observar uma prática que deveria estar "naturalmente inscrita no interior da casa, da morada, encerrada sob fechaduras, 
entre muros, a vida privada (...) enclausurada" (Duby 1990: 10). Corre-se o risco, portanto, de se olhar para inúmeros lugares errados.

Quanto à contribuição à história que teriam a dar os estudos sobre a vida privada, não resta dúvida de que é significativa, sob qualquer título: velha História das Mentalidades ou nova História Cultural. No final das contas, o que na verdade importa é a forma como os pesquisadores elaboram suas questões e as tentam responder com as suas fontes, podendo estar seu trabalho aprisionado (ou livre) em qualquer rótulo que se queira dar.

Feitas estas considerações, que imagino tangencialmente estarem em concordância com as opiniōes de Ronaldo Vainfas, cabem aqui pelo menos três pontos, não diria de discordância, mas de interrogações.

Creio que Ronaldo Vainfas exagera um pouco quando critica a novidade alardeada pelos organizadores da História da vida privada, afirmando que outras obras foram precursoras do que se considera hoje como História da Vida Privada. Realmente, em qualquer campo da história, pode ter havido obras com objetos ou temáticas semelhantes, mas há de se separar um ou outro estudo de uma tendência mais ampla de determinada época, em que historiadores privilegiam de maneira recorrente certos objetos e/ou. metodologia, justamente levando a que se definam títulos que os identifiquem entre si e os diferenciem dos outros. No caso da História da Vida Privada, entretanto, parece-me que esta definição passou um pouco ao largo do que chamamos de academia, como apontarei adiante.

O segundo ponto diz respeito à questão sobre a ausência da vida privada na coletânea Faire de l'Histoire, organizada por Jacques Le Goff e Pierre Nora. O que me pergunto é: por que teria de ter sido referida? Por outro lado, várias questões do que hoje se está afirmando como componentes da vida privada estavam presentes, embora sem este nome. O próprio autor creio que responde à questão, ao ressaltar o descaso da academia, na época, para com a obra de Philippe Ariès e ao fato de serem, no geral, os mesmos, os historiadores da velha História das Mentalidades e os da Vida Privada, o que me remete ao terceiro questionamento, talvez mais sério.

A impressão que tenho é a de que a coleção História da vida privada, organizada por Duby e Ariès, tornou-se mais um produto para mercado do que um conjunto de trabalhos para historiadores e estudiosos afins. Não há notas e não há muito compromisso com a comprovação empírica, salvo exceções. É uma obra que um "leigo" sempre pode pensar em obter, não só pelo intencional bonito formato, como também pela leitura "fácil". Nada tenho contra livros charmosos e - apelo de textos bem escritos, mas se a escrita é instrumento fundamental do historiador, não necessariamente ele é obrigado a ser um literato. Alguns o são, tanto melhor - podemos ter o prazer de ler um belo trabalho de história - mas estou convicta de que o que conta mesmo são as idéias com seus argumentos e comprovações, de que certamente carecem vários artigos da coletânea. Não teria sido, portanto, um pouco exagerado tomar tão a sério uma obra que se predispôs mais a divulgar do que a levantar questões para a história?

Apesar disto, considerei bastante pertinente o tratamento dado à análise da coletânea, o que surpreende num autor ligado às "mentalidades". $\bigcirc$ interessante é justamente utilizar quase de maneira irônica a quantificação, tão 
detratada por muitos dos que se dizem inseridos na temática "mentalidade/cultura", em particular no Brasil. Enquanto para a história social européia, das décadas de 1950 e 60, a quantificação aproximava-se do que seria uma história quase científica, o exagero oposto chegou a identificar como história econômica tudo o que pudesse ser contado, como se temas considerados como de "mentalidade" ou "cultura" fossem inadequados para a quantificação, - que com certeza não é o caso, principalmente para os que pensam que nada pode ser tão exclusivo ou excludente.

Em suma, penso que a multiplicidade e a variedade de enfoques, temáticas e métodos são mais válidas e lucrativas do que a tentativa de se forjar arbitrariamente uma unidade. 